\title{
Bacterial aetiological agents of intra-amniotic infections and preterm birth in pregnant women
}

\author{
George L. Mendz ${ }^{1 *}$, Nadeem O. Kaakoush ${ }^{2}$ and Julie A. Quinlivan ${ }^{3}$ \\ ' School of Medicine, Sydney, The University of Notre Dame Australia, Darlinghurst, NSW, Australia \\ 2 School of Biotechnology and Biomolecular Sciences, The University of New South Wales, Kensington, NSW, Australia \\ ${ }^{3}$ School of Medicine, Fremantle, The University of Notre Dame Australia, Fremantle, WA, Australia
}

Edited by:

Paul De Figueiredo, Texas A\&M

University, USA

Reviewed by:

Qing-Ming Qin, Jilin University,

China

Neetu Singh, Texas A\&M University,

USA

\section{*Correspondence:}

George L. Mendz, School of

Medicine, Sydney, The University of

Notre Dame Australia, 160 Oxford

St., Darlinghurst, NSW 2010,

Australia

e-mail:george.mendz@nd.edu.au
Infection-related preterm birth is a leading cause of infant mortality and morbidity; knowledge of bacterial populations invading the amniotic cavity and the routes of invasion is required to make progress in the prevention of preterm birth. Significant advances have been made in understanding bacterial communities in the vagina, but much less studied are intra-uterine bacterial populations during pregnancy. A systematic review of data published on the intra-uterine microbiome was performed; molecular information and summaries of species found in healthy individuals and in women with diagnosed infections served to construct a database and to analyse results to date. Thirteen studies fulfilled the review's inclusion criteria. The data of various investigations were collated, organized, and re-analyzed to achieve a more comprehensive understanding of microbial populations in the intra-amniotic space. The most common intra-amniotic bacterial taxa were species that can colonies the vagina in health and disease; there were others associated with the habitats of the mouth, gastrointestinal tract, and respiratory tract. The results suggest a central role for the ascending route of infections during pregnancy, and point to a possible secondary contribution via haematogenous invasion of the intra-amniotic space. The complete census of the intra-uterine microbiome awaits completion.

Keywords: microbiome, intra-uterine infection, preterm birth

\section{INTRODUCTION}

"Infections of mothers and their babies (both in utero and ex utero) are a major global challenge" (Hussein et al., 2011). Preterm birth (PTB) is the second largest direct cause of deaths in children younger than 5 years (Blencowe et al., 2012); it is a major cause of perinatal mortality and serious neonatal morbidity, and moderate to severe childhood disability in developed and developing countries (Lawn et al., 2005; Hemminki et al., 2007; Jacobsson, 2007). The burden of PTB is substantial and increased between 1990 and 2010 in developing and developed countries with reliable data (Blencowe et al., 2012). Length of gestation is considered to be a key indicator of infant health, and PTB is associated with poorer health outcomes in babies.

Premature deliveries can be classified into two broad groups: spontaneous and iatrogenic. The majority of PTB occur spontaneously as a result of preterm labor or preterm premature rupture of membranes. Spontaneous preterm delivery occurs in $\sim 12 \%$ of births in developed countries (Pretorius et al., 2007) and 14\% worldwide (Pararas et al., 2006). Iatrogenic PTB may be secondary to other complications of pregnancy such as preeclampsia, intrauterine growth restriction, abruptio placenta, or placenta praevia (Muglia and Katz, 2010).

"For much of the 20th century, PTB, defined as birth at less than 37 completed weeks of gestation, was viewed as an unpredictable and inevitable fact of life. Medical efforts thus focused on ameliorating the consequences of prematurity rather than preventing its occurrence. This approach resulted in improved neonatal outcomes, but it remains costly in terms of both the suffering of infants and their families and the economic burden on society." (Muglia and Katz, 2010). The burden of PTB increased during the last 30 years owing to significant improvements in neonatal care that made possible the survival of very preterm infants and resulted in a lowering of the threshold for preterm Caesarean delivery. Other factors that have contributed to higher rates of PTB are the multiple gestations arising from the use of assisted reproductive technologies, advanced maternal age, and improvements in obstetrics outcomes of surgical interventions to manage invasive lesions (Muglia and Katz, 2010).

The aetiology of PTB is multifactorial, and various factors have been identified as contributors to spontaneous PTB (Gracie et al., 2011), e.g., genetic, infection and inflammation, decidual haemorrhage, and environmental, behavioral and social stress (Figure 1). Infections have been long suspected to be the underlying cause of idiopathic PTB, and microbial intra-uterine infection is a confirmed leading cause of PTB. In particular, bacterial invasion of the amniotic cavity (BIAC) is the chief cause of neonatal mortality worldwide (Gonçalves et al., 2002; Lawn et al., 2005). Currently, there is overwhelming evidence to implicate infection in up to $40 \%$ of PTB cases, including intra-uterine (Ganu et al., 2013) and vaginal (Hyman et al., 2013) infections. Intra-amniotic infections are present in $\sim 50 \%$ of all pregnancies that result in PTB, and the earlier the gestational age at delivery, the higher the frequency of intra-amniotic infection (Burd et al., 2012). 


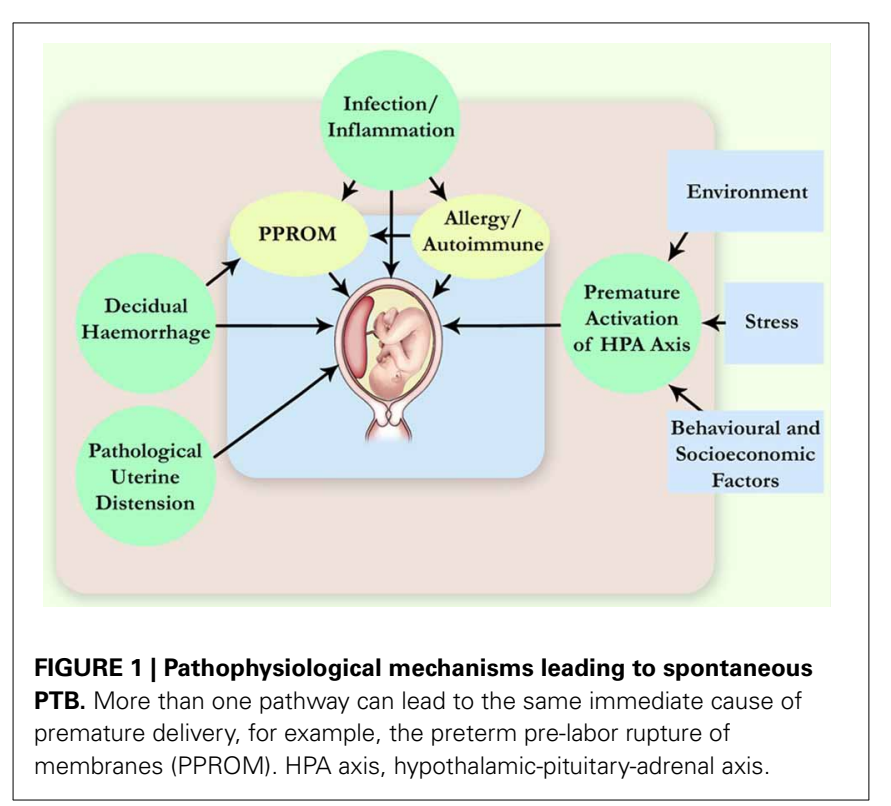

A study early in the twentieth Century supported the view that under normal circumstances and prior to labor, the amniotic cavity was sterile (Harris and Brown, 1927). The gold standard for identification of intrauterine infection has been the isolation of microbes in amniotic fluid sampled by amniocentesis. Owing to the finding that the amniotic fluid of less than $1 \%$ of women in labor at term contains culturable bacteria (Romero et al., 2002), historically the isolation of any microbes from the amniotic fluid was considered a pathological finding. However, investigations of the intra-uterine flora of women giving birth prematurely based on non-cultivation taxon-specific PCR analyses, as well as more recent studies employing non-cultivation broad-range PCR methods have demonstrated the presence of microflora in the intra-amniotic cavity even in the absence of any signs of infection (DiGiulio, 2012). The results of standard microbiological studies suggest that intrauterine infection accounts for as much as 25-45\% of spontaneous PTB (Zhou et al., 2010); but employing molecular techniques, bacterial footprints have been detected in as many as $60 \%$ of women delivering preterm (Gardella et al., 2004).

The sequence of events leading to PTB, progressing from intrauterine infection to pro-inflammatory cytokine activation, prostaglandin production, premature contractions, cervical changes, and premature delivery has been comprehensively studied on non-human primates (Adams Waldorf et al., 2011). In humans, the colonization of microbes and/or inflammation of the chorio-decidual interface can induce the production of a cascade of cytokines that result in an inflammatory response (Muglia and Katz, 2010). Bacteria also can have a more direct role in the pathogenesis of PTB by producing enzymes that degrade fetal membranes, or by inducing the synthesis and release of uterotonins such as prostaglandins, able to stimulate uterine contractions and cause preterm labor (Keelan et al., 2003; Lockwood, 2013).

Notwithstanding the evidence, current knowledge of BIAC is insufficient to develop effective strategies to prevent infection-related PTB because the prevalence, methods of diagnosis, pathogenicity mechanisms, and host susceptibilities to various bacteria require further investigations (DiGiulio, 2012). A necessary step to address these knowledge gaps is to obtain a complete understanding of the diverse microbial taxa involved in BIAC.

Pathogens may gain access to the amniotic cavity and fetus by ascending migration of the vaginal flora, haematogenous dissemination through the placenta, retrograde seeding from the peritoneal cavity through the Fallopian tubes, or iatrogenic introduction at the time of invasive procedures (Goldenberg et al., 2000). Evidence obtained from studies culturing bacteria supports the view that the most common pathway of BIAC is the ascending route (Romero and Mazor, 1988; DiGiulio, 2012).

This study reviews and organizes systematically data published on the identity and frequency of detection of bacterial taxa found in the intra-amniotic space of women who delivered preterm. Its focus is on the dramatic advance of the knowledge of the bacterial communities present in the genital microbiota of pregnant women made in the last 18 years by non-cultivation, highthroughput techniques of analysis, and the potential contributions systematic investigations of the female genital microbiome can make to preventing PTB.

\section{SOURCES AND STUDY SELECTION DATABASE SEARCHES}

An initial search of PubMed was conducted employing the broad concepts: "pregnancy," "preterm birth," and "intrauterine infection" or "chorioamnionitis," as well as appropriate synonyms and truncations via the Boolean search method. The searches returned up to 1242 titles. Adding the term "bacteria" reduced the number of publications to 328. The titles and abstracts of this list were examined, and a selection was made following the inclusion criteria for studies that: (1) were published between 1995 and 2013; (2) contained data on bacterial taxa in the uterus of pregnant women delivering preterm; and (3) employed cultivation or molecular methods of identification of bacterial species. Excluded were publications: (a) in a language other than English; and (b) that did not specify the type of microbes involved in the invasion of the amniotic space.

Perusal of the selected papers and references therein yielded 13 papers containing information required for this review (Jalava et al., 1996; Markenson et al., 1997; Gardella et al., 2004; DiGiulio et al., 2008, 2010a,b,c; Han et al., 2009; Jones et al., 2009; Srinivasan et al., 2009; Zhou et al., 2010; Marconi et al., 2011). The data from the selected studies were extracted to construct a database of intra-uterine bacterial taxa or genera identified in PTB and the frequencies at which they were found.

\section{PHYLOGENETIC ORGANIZATION}

Phylogenetic trees of various bacterial phyla and their respective orders, families, genera and species, were employed as templates to classify the identity of intrauterine bacterial genera and species found in pregnant women who gave birth before term. The process served to arrange bacterial taxa into appropriate phyla and orders according to the NCBI taxonomy database. 


\section{ANALYSES}

The frequency at which a taxon or genus was present was determined from the data in the 13 publications included in this study by adding the number of women with intrauterine infections who delivered preterm in which the taxon was found. The number of taxa in different phyla and orders were calculated in a similar way from the data in these publications.

\section{RESULTS AND CONCLUSIONS}

The review includes 761 women delivering before term of which 349 (46\%) presented with an intra-uterine infection. The use of non-culture direct-detection techniques has increased by $\sim 5$-fold the number of taxa known to be present in intrauterine infections during pregnancy.

Meta-analyses of randomized trials evaluating antibiotic treatments report statistically significant prolongation of pregnancy associated with the use of antibiotics in women with preterm labor and intact membranes (King and Flenady, 2002), and reduction in the delivered number of babies within $48 \mathrm{~h}$ in preterm premature rupture of the membranes (Kenyon et al., 2010). Thus, there is a strong association between the presence of some bacteria in the intra-amniotic cavity and PTB.

Bacteria belonging to a total of 5 phyla and 16 orders were found in the intra-uterine microbiota of the 349 pregnant women with intra-amniotic infection (Table 1, Figure 2). They belonged to 44 genera and more than 87 different taxa (identification of some bacteria was performed only at the genus level) (Table 1). The highest frequencies were determined for genera of the order Mycoplasmatales (59\%) and Lactobacillales (25\%) (Table 1).

Bacteria of the phylum Firmicutes were the most abundant and were detected in 343 women with infection included in this study; the second most common phylum among these women was Fusobacteria, found in 71 subjects (Figure 2). The phyla with larger number of different orders and taxa were Firmicutes and Proteobacteria (Table 1).

Taxa of the order Mycoplasmatales were found in 205 (58.7\%) women, and bacteria of the genus Ureaplasma were detected in 172 women (49\%). Recognized genital pathogenic species were found at high frequencies, e.g., Ureaplasma uralyticum (11\%), Streptococcus agalactiae (11\%), Mycoplasma hominis (9\%) and Fusobacterium nucleatum (9\%) (Table 1). These results are in broad agreement with previous more limited knowledge of BIAC. A review of the pathogens involved in sepsis in neonatal intensive care units found that the majority were mixed genital tract flora (Garland and Bowman, 2003). Meta-analyses of antibiotic administration to women with bacterial vaginosis showed an association of the treatment with a significant reduction in the incidence of PTB and low weight babies (Smaill, 2001). This work indicated taxa present at higher frequencies belonged to bacteria normally found in the urogenital and gastrointestinal tracts; a result that supports the view that most cases of chorioamnionitis arise from pathogens ascending from the vagina. Thus, it is reasonable to hypothesize that preventing ascending genital tract infection and the initiation of inflammatory cascades will reduce PTB, neonatal fever and other morbidities.
Table 1 | Bacteria found in the intra-uterine microbiota of the 349 pregnant women with intra-amniotic infection.

\begin{tabular}{llll}
\hline Phylum & Order & Species
\end{tabular}

(n)

\begin{tabular}{|c|c|c|c|}
\hline \multirow[t]{17}{*}{ Actinobacteria } & Actinomycetales & Actinomyces spp. & 1 \\
\hline & & Brachybacterium spp. & 1 \\
\hline & & Corynebacterium & 1 \\
\hline & & ammoniagenes & \\
\hline & & Corynebacterium & 1 \\
\hline & & amycolatum & \\
\hline & & Corynebacterium & 1 \\
\hline & & tuberculostearicum & \\
\hline & & Mobiluncus mulieris & 1 \\
\hline & & Propionibacterium acnes & 1 \\
\hline & & Propionibacterium spp. & 2 \\
\hline & & Rothia dentocariosa & 1 \\
\hline & Coriobacteriales & Atopobium vaginae & 2 \\
\hline & Bifidobacteriales & Bifidobacterium longum & 1 \\
\hline & & Bifidobacterium & 1 \\
\hline & & pseudolongum & \\
\hline & & Gardnerella vaginalis & 11 \\
\hline
\end{tabular}

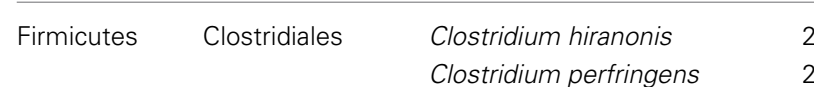

$\begin{array}{ll}\text { Clostridium perfringens } & 2 \\ \text { Eubacterium halii } & 1\end{array}$

Eubacteriun spp.

Faecalibacterium spp.

Filifactor alocis

Finegoldia magna

Peptoniphilus

assacharolyticus

Peptoniphilus lacrimalis $\quad 1$

Peptostreptococcus 1

oralis

Peptostreptococcus spp. 14

Oribacterium sinus

1

Erypsipelotricales Coprobacillus spp.

Mycoplasmatales Mycoplasmahominis 33

Ureaplasma parvum 22

Ureaplasma urealyticum 38

Ureaplasma spp. 112

Bacillales Listeria monocytogenes 2

Staphylococcus aureus 6

Staphylococcus 1

epidermis

Staphylococcus equorum 2

Staphylococcus 2

pettenkoferi

Staphylococcus spp. $\quad 6$

Lactobacillales Enterococcus faecalis 1

Enterococcus spp. 10

Lactobacillus crispatus 3

Lactobacillus delbrueckii 1

Lactobacillus gasseri 1

(Continued) 
Table 1 | Continued

\begin{tabular}{|c|c|c|c|}
\hline Phylum & Order & Species & $\begin{array}{c}\text { Frequency } \\
\text { (n) }\end{array}$ \\
\hline & & Lactobacillus iners & 1 \\
\hline & & Lactobacillus spp. & 3 \\
\hline & & Streptococcus agalactiae & 37 \\
\hline & & Streptococcus anginosus & 11 \\
\hline & & Streptococcus mitis & 10 \\
\hline & & Streptococcus oralis & 4 \\
\hline & & Streptococcus & 3 \\
\hline & & pneumoniae & \\
\hline & & Streptococcus salivarius & 1 \\
\hline & & Streptococcus spp. & 1 \\
\hline \multirow[t]{8}{*}{ Fusobacteria } & Fusobacteriales & Fusobacterium & 1 \\
\hline & & gonidoformans & \\
\hline & & Fusobacterium & 31 \\
\hline & & nucleatum & \\
\hline & & Fusobacterium spp. & 4 \\
\hline & & Leptotrichia amnionii & 5 \\
\hline & & Leptotrichia spp. & 17 \\
\hline & & Sneathia sanguinegens & 13 \\
\hline \multirow[t]{10}{*}{ Bacteroidetes } & Bacteroidales & Bacteroides fragilis & 4 \\
\hline & & Bacteroides & 1 \\
\hline & & xylanosolvens & \\
\hline & & Bacteroides spp. & 3 \\
\hline & & Prevotella bivia & 4 \\
\hline & & Prevotella copri & 2 \\
\hline & & Prevotella oris & 1 \\
\hline & & Prevotella spp. & 3 \\
\hline & Flavobacteriales & Bergeyella spp. & 1 \\
\hline & & Myroides spp. & 1 \\
\hline \multirow[t]{18}{*}{ Proteobacteria } & Campylobacterales & $\begin{array}{l}\text { Campylobacter } \\
\text { ureolyticus }\end{array}$ & 3 \\
\hline & & Campylobacter spp. & 1 \\
\hline & Neisseriales & Kingella denitrificans & 1 \\
\hline & & Neisseria cinerea & 1 \\
\hline & & Neisseria subflava & 1 \\
\hline & & Neisseria spp. & 1 \\
\hline & Burkholderiales & Delftia acidovioans & 1 \\
\hline & Pasteurellales & $\begin{array}{l}\text { Haemophilus } \\
\text { haemoglobinophilus }\end{array}$ & 1 \\
\hline & & Haemophilus influenza & 10 \\
\hline & & Haemophilus & 2 \\
\hline & & parainluenza & \\
\hline & & Haemophilus quentini & 1 \\
\hline & Enterobacteriales & Citrobacter koseri & 1 \\
\hline & & Enterobacter aerogenes & 1 \\
\hline & & Enterobacter spp. & 2 \\
\hline & & Escherichia coli & 25 \\
\hline & & Proteus mirabilis & 4 \\
\hline & & Shigella spp. & 2 \\
\hline
\end{tabular}

The frequency is given as the number of women (n) carrying a particular species.

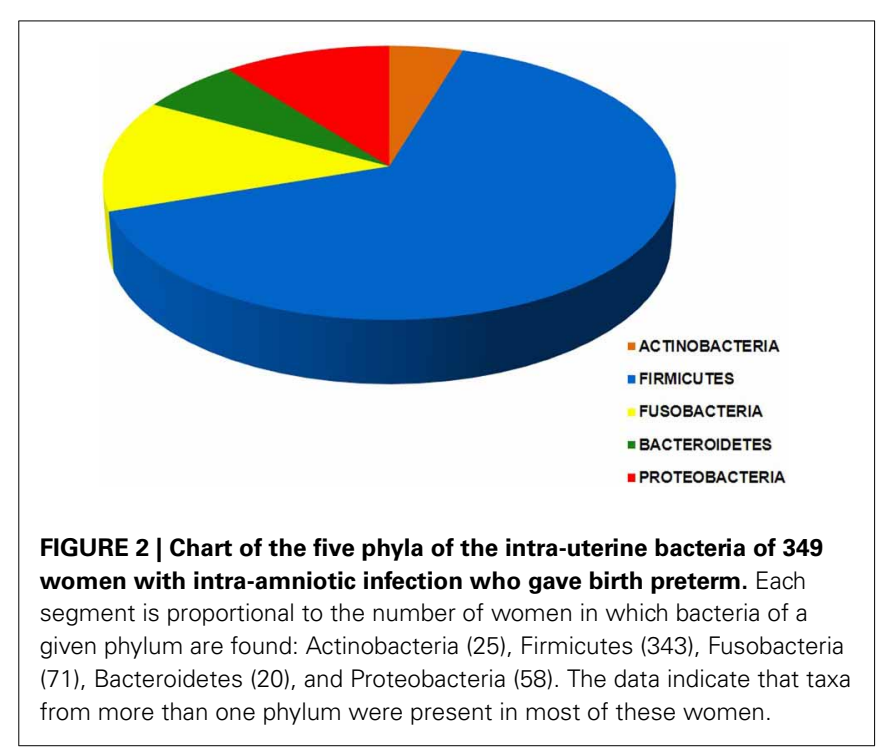

Pathogens that are ordinarily found in the gastrointestinal tract and may reach the vagina, also can cause haematogenous invasion of the uterus. Listeria monocytogenes crosses the mucosal barrier of the intestine to disseminate haematogenously to any site, with a unique tendency to infect the fetoplacental unit (Baud and Greub, 2011). Generally, the bacteremia manifests clinically as non-specific influenza-like symptoms, and may remain asymptomatic. A review of 36 cases of maternofetal listeriosis showed that the mothers generally were affected mildly by the infection. Twelve pregnancies ended with abortion or stillbirth; among the children born alive, 15 were diagnosed with bacteremia/septicemia, 3 with pneumonia, 3 with neonatal meningitis, 1 died, and 3 were unaffected (Smith et al., 2009).

There is evidence to support the hypothesis that bacterial infections at sites distant from the urogenital tract, in particular the oronasal cavity and the respiratory tract, may be important causes of preterm labor probably through the activation of abnormal inflammatory responses within the uterus and intrauterine tissues. Data from clinical and animal studies on maternal periodontal status combined with a biologically plausible mechanism provide strong evidence for a negative impact of periodontal infection on pregnancy outcome (Baskaradoss et al., 2012).

\section{BIAC BY ORONASAL MICROFLORA}

This review showed that a number of taxa found in periodontal disease were associated with PTB; they had a frequency of $c a .13 \%$ in women delivering before term. Identified taxa of the oronasal habitat included Bergeyella spp., Dialister spp., Fusobacterium nucleatum, Oribacterium sinus, Peptostreptococcus oralis, Prevotella oris, Rothia dentocariosa, Streptococcus oralis, Streptococcus salivarius, Veillonella parvula, and Veillonella spp. It should be noted that many of these taxa are frequently detected in faces, e.g., S. salivarius and F. nucleatum; and in the vagina, e.g., P. oralis, P. oris, S. salivarius, Veillonella spp., and Dialister spp.

Using $16 \mathrm{~S}$ and $23 \mathrm{~S}$ rDNA molecular methods, a Bergeyella spp. strain detected in the amniotic fluid of a pregnant woman with clinical intrauterine infection and histologic necrotizing acute 
and chronic chorioamnionitis was detected also in the subgingival plaque of the patient but not in her vaginal tract. The results suggested that the woman's intrauterine infection with this Bergeyella strain originated from the oral cavity (Han et al., 2006). Capnocytophaga spp. are part of the normal human oral bacterial flora, but as opportunistic pathogens can produce extra-oral infections including septicaemia and, less commonly, chorioamnionitis and neonatal infections. Evidence suggests that a number of cases of intra-amniotic infection with this bacterium occurred by the ascending route, but several cases that involved early-onset of sepsis due to Capnocytophaga spp. infection yielded no vaginal cultures of this bacterium suggesting haematogenous spread from the oral cavity (Lopez et al., 2010).

Evidence that the oral pathogen F. nucleatum may be transmitted haematogenously to the placenta and cause adverse pregnancy outcomes was obtained in pregnant mice injected intravenously with the bacterium. F. nucleatum colonizes the placenta and proliferates rapidly, inducing fetal death by localized infection inside the uterus; the bacterial infection was restricted inside the uterus, without spreading systemically (Han et al., 2004).

The bacterium Rothia dentocariosa is a common inhabitant of the human oral cavity where it rarely causes serious infections; it has been associated with endocarditis, pneumonia, septicemia, and abscesses in adults. $R$. dentocariosa caused septicemia in a neonatal infant with meconium aspiration syndrome (Shin et al., 2004), and was detected in the blood of a stillborn baby (Karlsson and Jacobsson, 2005). Its presence in the vagina is rare; only one woman with no signs of infection was reported in a study comprising 394 subjects (Ravel et al., 2011). The infrequent detection of this bacterium in the vagina makes it plausible that in the cases of neonatal septicemia and the stillborn infant, the access to the intra-amniotic cavity occurred via the haematogenous pathway.

Streptococcus oralis has been found in the intra-amniotic cavity (Jalava et al., 1996), and was associated with PTB in a study comparing women delivering preterm or at term (Skuldbøl et al., 2006), but the routes of invasion were not established in these studies.

A clinical study of 812 deliveries from a cohort study of pregnant mothers entitled "Oral Conditions and Pregnancy" demonstrated that both antepartum maternal periodontal disease and incidence/progression of periodontal disease are associated with PTB and growth restriction after adjusting for traditional obstetric risk factors. The results support the concept that maternal periodontal infection in the absence of a protective maternal antibody response is associated with systemic dissemination of oral organisms that translocate to the fetus resulting in prematurity (Madianos et al., 2001). Analysis of oral bacteria in the amniotic cavity of women delivering preterm agreed with the results of a meta-analysis of 12,047 pregnant women that found a 2.73 overall odds ratio (95\% CI: $2.06-3.6, p<0.0001$ ) of giving premature birth to a child for mothers with periodontitis (Konopka and Paradowska-Stolarz, 2012). These findings provide support for the hypothesis that haematogenous dissemination of oronasal bacteria is probably one of their routes of access to the amniotic cavity.

\section{BIAC BY RESPIRATORY TRACT MICROFLORA}

Haematogenous spreading of infections from the upper or lower airways to the placenta may occur at any stage of the pregnancy (Sandu et al., 2013). The data collected in this review indicated that in the intra-amniotic cavity of women giving birth preterm were found at low frequencies bacteria that colonies the respiratory tract such as Haemophilus influenza, Haemophilus parainfluenza, and Streptococcus pneumoniae.

Although these and other respiratory tract pathogens have been found in the vaginal microbiota (Ravel et al., 2011), in mothers with acute respiratory infection induced by highly virulent pathogens, the infection may spread haematogenously to the placenta inducing spontaneous and/or septic abortions, premature births, fetal damage or intra-uterine fetal death (Sandu et al., 2013). Pregnant women with pulmonary tuberculosis have higher odds of PTB (Asuquo et al., 2012). In a stillbirth where the mother had an upper respiratory infection of F. nucleatum, the bacterium was isolated from the placenta and the infant, and the same clone was identified in her subgingival plaque, but not in the vagina or rectum (Han et al., 2010).

Haemophilus influenzae is primarily responsible for neonatal meningitis and respiratory tract infections in children. It has a low prevalence rate in genital tract cultures and rarely causes acute endometritis, but intra-amniotic infection and positive blood cultures have been reported (Shute and Kimber, 1994). A sepsis secondary to an acute $H$. influenzae infection led to placental abruption and spontaneous abortion (Calner et al., 2012); also a case has been reported with the uterus as the primary focus of sepsis with presence of the bacterium in blood but not in the vagina (Martin et al., 2013). Vertical transmission of H. influenzae appears to be the most common route of infection of the fetus, but ascending infections are less common in $H$. parainfluenzae infections (Garcia et al., 1997).

Reports indicate involvement of oral and, less commonly, respiratory tract pathogens in intra-uterine infections. The presence of the same bacterium at the original point of infection and in the uterus supports a causal relationship and a role for haematogenous BIAC during pregnancy that could lead to PTB.

Streptococcus pneumoniae is a common pathogen of the general population; it is a frequent cause of pneumonias, meningitis, bacteremia, and sepsis. This bacterium is uncommon in the vaginal flora and is rarely associated with gynecologic infections, but has been found in intra-amniotic infections causing septic abortions with no evidence of vaginal infection (Liang and Yeh, 2005). In a study of 29 cases of $S$. pneumonia infection of neonates, one mother had bacterial infection at delivery and clinical amnionitis (Hoffman et al., 2003).

The vast majority of the genera identified in intra-amniotic infections belong to bacteria found in the indigenous human microbiota. Leaving out exogenously acquired bacteria, and considering that more than a trillion microbes inhabit body surfaces and cavities, and outnumber human cells by at least a factor of 10 , the human body is a rich potential source for opportunistic BIAC. Pathogens residing in body sites that could access the ascending migration or haematogenous route will influence the diversity and abundance of bacteria in the amniotic fluid. 


\section{FUTURE RESEARCH}

Amongst newborns, low and very low weight infants are at the highest risk of early death or disability, thus, a major focus of research in Obstetrics should be a better understanding of the processes that lead to PTB and the development of preventive interventions (Lockwood, 2013).

"Future efforts to reduce the rate of PTB depend upon gaining an improved understanding of the causative mechanism(s), determining differences in individual susceptibility, and identifying specific early-stage biomarkers that will allow the development of novel and timely intervention strategies." (Hussein et al., 2011).

In the last 15 years, the significant progress made in the knowledge of the diversity of bacterial communities in the female genital tract and the role of bacterial infections in PTB wrought by novel sequencing techniques and bioinformatics tools, have made reduction of PTB a goal achievable by research directed toward prevention of BIAC by pathogens.

Considering the limitations of studies based on bacterial cultivation to reveal all the microflora present, new comprehensive investigations employing non-culture methods and stateof-the-art sequencing analyses are required to establish the intra-uterine microbiome in health and disease. A complete census of the intra-uterine microbiota during pregnancy conducted concurrently with a census of the vaginal microbiome

\section{REFERENCES}

Adams Waldorf, K. M., Rubens, C. E., and Gravett, M. G. (2011). Use of nonhuman primate models to investigate mechanisms of infection-associated preterm birth. BJOG 118, 136-144. doi: 10.1111/j.14710528.2010.02728.x

Asuquo, B., Vellone, A. D., Walters, G., Manney, S., Miquimi, L., and Kurst, H. (2012). A case-control study of teh risk of adverse perinatal outcomes due to tuberculosis during pregnancy. J. Obstet. Gynaecol. 32, 635-638. doi: 10.3109/01443615. 2012.704436

Baskaradoss, J. K., Geevarghese, A., and Al Dosari, A. A.-F. (2012). Causes of adverse pregnancy outcomes and the role of maternal periodontal status -A review of the literature. Open. Dent. J. 6, 79-84. doi: 10.2174/187421060120 6010079

Baud, D., and Greub, G. (2011). Intracellular bacteria and adverse pregnancy outcomes. Clin. Microbiol. Infect. 17, 1312-1322. doi: 10.1111/j.14690691.2011.03604.x

Blencowe, H., Cousens, S., Oestergaard, M. Z., Chou, D., Moller, A. B., Narwal, R., et al. (2012). National, regional, and worldwide estimates of preterm birth rates in the year 2010 with time trends since 1990 for selected countries: a systematic analysis and implications. Lancet
379, 2162-2172. doi: 10.1016/ S0140-6736(12)60820-4

Burd, I., Balakrishnan, B., and Kannan, S. (2012). Models of fetal brain injury, intrauterine inflammation, and preterm birth. Am. J. Reprod. Immunol. 67, 287-294. doi: 10.1111/ j.1600-0897.2012.01110.x

Calner, P. A., Salinas, M. L., Steck, A., and Schechter-Perkins, E. (2012). Haemophilus influenzae sepsis and placental abruption in an unvaccinated immigrant. West. J. Emerg. Med. 13, 133-135. doi: 10.5811/ westjem.2011.7.6783

DiGiulio, D. B. (2012). Diversity of microbes in amniotic fluid. Semin. Fetal Neonatal Med. 17, 2-11. doi: 10.1016/j.siny.2011.10.001

DiGiulio, D. B., Gervasi, M. T., Romero, R., Vaisbuch, E., Mazaki-Tovi, S., Kusanovic, J. P., et al. (2010a). Microbial invasion of the amniotic cavity in pregnancies with small-for-gestational-age fetuses. J. Perinat. Med. 38, 495-502. doi: 10.1515/JPM.2010.076

DiGiulio, D. B., Gervasi, M. T., Romero, R., Mazaki-Tovi, S., Vaisbuch, E., Kusanovic, J. P., et al. (2010b). Microbial invasion of the amniotic cavity in preeclampsia as assessed by cultivation and sequence-based methods. J. Perinat. Med. 38, 503-513. doi: 10.1515/jpm.2010.078

DiGiulio, D. B., Romero, R., Kusanovic, J. P., Gómez, R., Kim, C. J., Seok, K. S., et al. (2010c). Prevalence and

will serve to outline the characteristics of the bacterial communities in the female genital tract; in particular, the elucidation of the microbial intra-uterine populations in healthy pregnant women, as well as the contribution of ascending infections to BIAC.

Future investigations that establish with more accuracy the bacterial taxa found in association with PTB, as well as their routes of invasion of the intra-amniotic cavity will provide important knowledge to support the development of earlier and more specific diagnostic methods of maternal genital infections. This will result in better targeted and more effective treatments, including many infections that presently are clinically silent and can cause significant morbidity in fetuses and infants. A full understanding of the female urogenital microbiome will render these infections amenable to intervention and will have an impact in the prevention of PTB.

\section{ACKNOWLEDGMENTS}

This study was supported by a grant from the Research Foundation of the Cerebral Palsy Alliance of Australia. The authors are grateful for the contribution of E. L. Menendez to the compilation a large data set of bacteria found in the intraamniotic space, their phylogeny, their primary locations in the human body, and the diseases they cause.

diversity of microbes in the amniotic fluid, the fetal inflammatory response, and pregnancy outcome in women with preterm pre-labor rupture of membranes. Am. J. Reprod. Immunol. 64, 38-57. doi: 10.1111/j.1600-0897. 2010.00830.x

DiGiulio, D. B., Romero, R., Amogan, H. P., Kusanovic, J. P., Bik, E. M. Gotsch, F., et al. (2008). Microbial prevalence, diversity and abundance in amniotic fluid during preterm labor: a molecular and culture-based investigation. PLoS ONE 3:e3056. doi: 10.1371/journal. pone. 0003056

Ganu, R. S., Ma, J., and Aagaard, K. M. (2013). The role of microbial communities in parturition: is there evidence of association with preterm birth and perinatal morbidity and mortality. Am. J. Perinatol. 30, 613-624. doi: 10.1055/s-0032-1329693

Garcia, E., Andreu, A., and Bartolomé, R. M. (1997). Maternalfetal vertical transmission of Haemophilus influenzae and Haemophilus parainfluenzae. Enferm. Infecc. Microbiol. Clin. 15, 65-69.

Gardella, C., Riley, D. E., Hitti, J., Agnew, K., Krieger, J. N., and Eschenbach, D. (2004). Identification and sequencing of bacterial rDNAs in culturenegative amniotic fluid from women in premature labor. Am.
J. Perinatol. 21, 319-323. doi: 10.1055/s-2004-831884

Garland, S. M., and Bowman, E. D. (2003). Reappraisal of C-reactive protein as a screening tool for neonatal sepsis. Pathology 35, 240-243. doi: 10.1080/ 0031302031000123227

Goldenberg, R. L., Hauth, J. C., and Andrews, W. W. (2000). Intrauterine infection and preterm delivery. N. Engl. J. Med. 342, 1500-1507. doi: 10.1056/ NEJM200005183422007

Gonçalves, L. F., Chaiworapongsa, T., and Romero, R. (2002). Intrauterine infection and prematurity. Ment. Retard. Dev. Disabil. Res. Rev. 8, 3-13. doi: 10.1002/mrdd.10008

Gracie, S., Pennell, C., EkmanOrdeberg, G., Lye, S., McManaman, J., Williams, S., et al. (2011). An integrated systems biology aproach ot the study of preterm birth using "-omic" technology -a guideline for research. BMC Prenancy Childbirth 11:71. doi: 10.1186/14712393-11-71

Han, Y. W., Fardini, Y., Casey Chen, C., Iacampo, K. G., Peraino, V. A., Shamonki, J. M., et al. (2010). Term stillbirth caused by oral Fusobacterium nucleatum. Obstet. Gynecol. 115, 442-445. doi: 10.1097/AOG. 0b013e3181cb9955

Han, Y. W., Ikegami, A., Bissada, N. F., Herbst, M., Redline, R. W., and Ashmead, G. G. (2006). 
Transmission of an uncultivated Bergeyella strain from the oral cavity to amniotic fluid in a case of preterm birth. J. Clin. Microbiol. 44, 1475-1483. doi: 10.1128/JCM.44.4. 1475-1483.2006

Han, Y. W., Redline, R. W., Mei, L., Yin, L. C., Hill, G. B., and McCormick, T. S. (2004). Fusobacterium nucleatum induces premature and term stillbirths in pregnant mice: implication of oral bacteria in preterm birth. Infect. Immun. 72, 2272-2279. doi: 10.1128/IAI.72.4.2272-2279.2004

Han, Y. W., Shen, T., Chung, P., Buhimschi, I. A., and Buhimschi, C. S. (2009). Uncultivated bacteria as etiologic agents of intra-amniotic inflammation leading to preterm birth. J. Clin. Microbiol. 47, 38-47. doi: 10.1128/JCM.01206-08

Harris, J. W., and Brown, H. (1927). Bacterial content of the uterus at cesarean section. Am. J. Obstet. Gynecol. 113, 133.

Hemminki, K., Li, X., Sundquist, K., and Sundquist, J. (2007). High familial risks for cerebral palsy implicate partial heritable aetiology. Paediatr. Perinat. Epidemiol. 21, 235-241. doi: 10.1111/j.1365-3016. 2007.00798.x

Hoffman, J. A., Mason, E. O., Schutze, G. E., Tan, T. Q., Barson, W. J., Givner, L. B., et al. (2003). Streptococcus pneumoniae infections in the neonate. Pediatrics 112, 1095-1102. doi: 10.1542/peds.112.5.1095

Hussein, J., Ugwumadu, A., and Witkin, S. (2011). Editor's choice. BJOG 118, i-ii.

Hyman, R. W., Fukushima, M., Jiang, H., Fung, E., Rand, L., Johnson, B., et al. (2013). Diversity of the Vaginal microbiome correlates with preterm birth. Reprod. Sci. doi: 10.1177/ 1933719113488838. [Epub ahead of print].

Jacobsson, B. (2007). A report: the definition and classification of cerebral palsy April 2006. Dev. Med. Child Neurol. Suppl. 109, 8-14.

Jalava, J., Mäntymaa, M. L., Ekblad, U., Toivanen, P., Skurnik, M., Lassila, O., et al. (1996). Bacterial 16S rDNA polymerase chain reaction in the detection of intra-amniotic infection. Br. J. Obstet. Gynaecol. 103, 664-669. doi: 10.1111/j.1471-0528. 1996.tb09835.x

Jones, H. E., Harris, K. A., Azizia, M., Bank, L., Carpenter, B., Hartley, J. C., et al. (2009). Differing prevalence and diversity of bacterial species in fetal membranes from very preterm and term labor. PLoS ONE 4:e8205. doi: 10.1371/journal. pone. 0008205
Karlsson, M. D., and Jacobsson, B. (2005). Intrauterine fetal death associated with Rothia dentocariosa: a case report. Am. J. Obstet. Gynecol. 197, e6-e7. doi: 10.1016/j.ajog. 2007.08.024

Keelan, J. A., Blumenstein, M., Helliwell, R. J., Sato, T. A., Marvin, K. W., and Mitchell, M. D. (2003). Cytokines, prostaglandins and parturition-a review. Placenta 24(Suppl. A), S33-S46. doi: 10.1053/plac.2002.0948

Kenyon, S., Boulvain, M., and Neilson, J. (2010). Antibiotics for preterm rupture of membranes. Cochrane Database Syst. Rev. 2, CD001058.

King, J., and Flenady, V. (2002). Prophylactic antibiotics for inhibiting preterm labour with intact membranes. Cochrane Database Syst. Rev. 4, CD000246. doi: 10.1002/14651858.CD000246

Konopka, T., and Paradowska-Stolarz, A. (2012). Periodontitis and risk of preterm birth and low birthweighta meta-analysis. Ginekol Pol. 83, 446-453.

Lawn, J. E., Cousens, S., Zupan, J. (2005). 4 million neonatal deaths: Where? Why? Lancet 365, 891-900. doi: $\quad 10.1016 /$ S0140-6736(05) 71048-5

Liang, S., and Yeh, J. (2005). Septic Abortion due to Streptococcus pneumoniae. Department of Medicine, UCLA. Available online at: http://www.med.ucla.edu/modules/ wfsection/article.php?articleid $=271$

Lockwood, C. J. (2013). Pathogenesis of Spontaneous Preterm Birth. Available online at: http://www. uptodate.com/contents/pathogenesis-ofspontaneous-preterm-birth

Lopez, E., Raymond, J., Patkai, J., El Ayoubi, M., Schmitz, T., Moriette, G., et al. (2010). Capnocytophaga species and prterm birth: case series and review of the literature. Clin. Microbiol. Infect. 16, 1539-1543. doi: 10.1111/j.1469-0691.2010.03151.x

Madianos, P. N., Lieff, S., Murtha, A. P., Boggess, K. A., Auten, R. L., Beck, J. D., et al. (2001). Maternal periodontitis and prematurity. Part II: maternal infection and fetal exposure. Ann. Periodontol. 6, 175-182. doi: 10.1902/annals.2001.6.1.175

Marconi, C., de Andrade Ramos, B. R., Peraçoli, J. C., Donders, G., G., and da Silva, M. G. (2011). Amniotic fluid interleukin-1 beta and interleukin-6, but not interleukin-8 correlate with microbial invasion of the amniotic cavity in preterm labor. Am. J. Reprod. Immunol. 65, 549-556. doi: 10.1111/j.16000897.2010.00940.x
Markenson, G. R., Martin, R. K., Tillotson-Criss, M., Foley, K. S., Stewart, R. S. Jr., and Yancey, M. (1997). The use of the polymerase chain reaction to detect bacteria in amniotic fluid in pregnancies complicated by preterm labor. Am. J. Obstet. Gynecol. 177, 1471-1477. doi: 10.1016/S00029378(97)70093-0

Martin, D., Dbouk, R. H., DeleonCarnes, M., del Rio, C., and Guarner, J. (2013). Haemophilus influenza acute endometritis with bacteremia: case report and literature review. Diagn. Microbiol. Infect. Dis. 76, 235-236. doi 10.1016/j.diagmicrobio.2013.02.010

Muglia, L. J., and Katz, M. (2010). The enigma of spontaneous preterm birth. N. Engl. J. Med. 362, 529-535. doi: 10.1056/NEJMra0904308

Pararas, M. V., Skevaki, C. L., and Kafetzis, D. A. (2006). Preterm birth due to maternal infection: causative pathogens and modes of prevention. Eur. J. Clin. Microbiol. Infect. Dis. 25 , 562-569. doi: 10.1007/s10096-0060190-3

Pretorius, C., Jagatt, A., and Lamont, R. F. (2007). The relationship between periodontal disease, bacterial vaginosis, and preterm birth. J. Perinat. Med. 35, 93-99. doi: 10.1515/JPM.2007.039

Ravel, J., Gajer, P., Abdo, Z., Schneider, G. C., Koenig, S. S. K., McCulle, S. L., et al. (2011). Vaginal microbiome of reproductive-age women. Proc. Natl. Acad. Sci. U.S.A. 108(Suppl. 1), 4680-4687. doi: 10.1073/pnas.1002611107

Romero, R., Espinoza, J., Chaiworapongsa, T., and Kalache, K. (2002). Infection and prematurity and the role of preventive strategies. Semin. Neonatol. 7, 259-274. doi: 10.1016/S1084-2756(02)90121-1

Romero, R., and Mazor, M. (1988). Infection and preterm labor. Clin. Obstet. Gynecol. 31, 553-584. doi: 10.1097/00003081-19880900000006

Sandu, C., Folescu, R., Pop, E., and Motoc, A. G. M. (2013). Hematogenous placental infection in acute respiratory infections. Rom. J. Morphol. Embryol. 54, 157-161.

Shin, J. H., Shim, J. D., Kim, H. R., Sinn, J. B., Kook, J. K., and Lee, J. N. (2004). Rothia dentocariosa septicemia without endocarditis in a neonatal infant with meconium aspiration syndrome. J. Clin. Microbiol. 42, 4891-4892. doi 10.1128/JCM.42.10.4891-4892.2004

Shute, K. M., and Kimber, R. G. (1994). Haemophilus influenzae intra-amniotic infection with intact membranes. J. Am. Board Fam. Pract. 7, 335-341.

Skuldbøl, T., Johansen, K. H., Dahlén, G., Stoltze, K., and Holmstrup, P. (2006). Is pre-term labour associated with periodontitis in a Danish maternity ward. J. Clin. Periodontol. 33, 177-183. doi: 10.1111/j.1600051X.2006.00899.x

Smaill, F. (2001). Antibiotics for asymptomatic bacteriuria in pregnancy. Chocrane Database Syst. Rev. 2, CD000490. doi: 10.1002/14651858.CD000490.pub2

Smith, B., Kemp, M., Ethelberg, S., Schiellerup, P., Bruun, B. G., Gerner-Smidt, P., et al. (2009). Listeria monocytogenes: maternalfoetal infections in Denmark 1994-2005. Scand. J. Infect. Dis. 41, 21-25. doi: $10.1080 / 00365540802468094$

Srinivasan, U., Misra, D., Marazita, M. L., and Foxman, B. (2009). Vaginal and oral microbes, host genotype and preterm birth. Med. Hypotheses 73, 963-975. doi: 10.1016/j.mehy.2009.06.017

Zhou, X., Brotman, R., Gajer, P., Abdo, Z., Schüette, U., Ma, S., et al. (2010). Recent advances in understanding the microbiology of the female reproductive tract and the causes of premature birth. Infect. Dis. Obstet. Gynaecol. 2010, 737425. doi: $10.1155 / 2010 / 737425$

Conflict of Interest Statement: The authors declare that the research was conducted in the absence of any commercial or financial relationships that could be construed as a potential conflict of interest.

Received: 28 July 2013; accepted: 16 September 2013; published online: 16 October 2013.

Citation: Mendz GL, Kaakoush NO and Quinlivan JA (2013) Bacterial aetiological agents of intra-amniotic infections and preterm birth in pregnant women. Front. Cell. Infect. Microbiol. 3:58. doi: 10.3389/fcimb.2013.00058

This article was submitted to the journal Frontiers in Cellular and Infection Microbiology

Copyright () 2013 Mendz, Kaakoush and Quinlivan. This is an open-access article distributed under the terms of the Creative Commons Attribution License (CC BY). The use, distribution or reproduction in other forums is permitted, provided the original author(s) or licensor are credited and that the original publication in this journal is cited, in accordance with accepted academic practice. No use, distribution or reproduction is permitted which does not comply with these terms. 